\title{
Experimental Analysis of Mixture Formation Process in Gasoline Spray with Laser Induced Exciplex Fluorescence Technique
}

\author{
Dai Matsuda ${ }^{1}$, Eriko Matsumura ${ }^{2}$, Jiro Senda ${ }^{2}$ \\ ${ }^{1}$ Department of Mechanical Engineering, Doshisha University, Kyoto, Japan \\ 2 Department of Science and Mechanical Engineering, Doshisha University, Kyoto, Japan \\ ${ }^{*}$ Corresponding author email : cyjg1502@mail4.doshisha.ac.jp
}

\begin{abstract}
This paper reports the experimental analysis of mixture formation process with Laser Induced Exciplex Fluorescence (LIEF) for the unsteady evaporating gasoline spray. The exciplex fluorescence technique, developed by Melton, is a method to optically separate the fluorescence from the liquid and vapor phases, but the quantitative analysis of vapor concentration in the two-phase mixture region of liquid and vapor is difficult due to the fluorescence cross talk. In this study, an image processing method was developed to calculate the vapor concentration in the two-phase mixture region of liquid and vapor using the average temperature of the mixture. This method considering the fluorescence crosstalk between the liquid and vapor phases was applied to analyse the gasoline fuel spray at different fuel injection pressures. It was found that the liquid phase concentration in the mixture decreased with increasing the fuel injection pressure.
\end{abstract}

Keywords: Mixture formation, Evaporation, Laser induced exciplex fluorescence, Cross talk.

\section{Introduction}

In direct injection gasoline engines, the fuel is injected into the cylinder and forms mixture with the ambient gas through atomization and evaporation. The characteristics of the mixture have a great influence on the engine performance and exhaust characteristics through ignition and combustion. Various methods have been proposed for the measurement of evaporating fuel sprays, such as Rayleigh scattering [1], laser-induced fluorescence (LIF) [2], laser-induced exciplex fluorescence (LIEF) [3], which obtain cross-sectional information, Infrared extinction scattering (IRES) [4], and laser lights absorbed and scattered (LAS) [5], which obtain line of sight information. However, it is very difficult to separate and measure simultaneously the liquid and vapor phases with spatial distribution of concentration and temperature due to the unsteady behaviour of fuel spray. Therefore, there are no studies that investigate in detail the effect of the spray on the evaporation process. The authors selected fuels and fluorescent tracers that are similar to the evaporation characteristics of gasoline and proposed a method to treat the pressure dependence and temperature dependence of the fluorescence intensity [6]. The vapor concentration in the two-phase mixture region of liquid and vapor was quantified by image processing that consider the fluorescence crosstalk of the liquid and vapor phases [7]. The effects of fuel injection pressure on the mixture formation were investigated.

\section{Laser-induced exciplex fluorescence technique (LIEF)}

The exciplex fluorescence technique was developed by Melton to separate and visualize the liquid and vapor phases [8][9]. When two fluorescent tracers are added to the fuel and irradiated with a laser beam in their absorption bands, an excited dimer is formed at high concentration, and new fluorescence appears at longer wavelengths than that of the component monomers. The new fluorescence is called exciplex fluorescence. In general, the fluorescence of the liquid phase is much larger than that of the vapor phase, which makes it 
difficult to measure the vapor concentration. Therefore, it is necessary to select a combination and mixing ratio of fuel and fluorescent tracers in which the fluorescence intensity of the vapor phase can be measured and the fluorescence intensity of the liquid phase is relatively small. In addition, to simulate the evaporation characteristics of fuel, the evaporation characteristics of the fluorescent tracers must be sufficiently similar to those of the fuel.

In this study, isooctane (92 vol\%), which does not fluoresce under incident light, to simulate the evaporation characteristics of gasoline, benzene (4 vol\%) and triethylamine (4 vol\%) as fluorescent tracers that emit monomer fluorescence and exciplex fluorescence were selected [6][10]. The difference between the saturation temperature of the fuel and the tracer is $22 \mathrm{~K}$ under the experimental conditions of the ambient pressure is $0.28 \mathrm{MPa}$. The fluorescence spectra of the vapor and liquid phases of mixed fuel were measured by a spectrometer (Hamamatsu Photonics: C8808-01 PMA-11) at an incident wavelength of $266 \mathrm{~nm}$, and the transmission characteristics of the bandpass filter used for fluorescence spectroscopy are shown in Figure1. The fluorescence spectrum of the vapor phase is monomer fluorescence with a peak around $280 \mathrm{~nm}$, and the fluorescence spectrum of the liquid phase is exciplex fluorescence with a peak around $340 \mathrm{~nm}$, but monomer fluorescence around $280 \mathrm{~nm}$ remains. Filter $\mathrm{A}$ has a transmittance near the incident wavelength, and the scattering of the droplet is measured. Filter B has a transmittance around $285 \mathrm{~nm}$, and the monomer fluorescence of the vapor phase and the monomer fluorescence of the liquid phase is measured. The monomer fluorescence around $285 \mathrm{~nm}$ is mixed information of vapor and liquid. Filter $\mathrm{C}$ has a transmittance around $343 \mathrm{~nm}$, and the monomer fluorescence of the vapor phase and the exciplex fluorescence of the liquid phase is measured. The monomer fluorescence around $343 \mathrm{~nm}$ is noise-level. Therefore, it is considered that the only exciplex fluorescence of the liquid phase is measured by filter $\mathrm{C}$. The concentration information of the vapor phase can be obtained from the monomer fluorescence measured by filter $\mathrm{B}$. However, the vapor concentration was overestimated if the crosstalk of monomer fluorescence of the liquid phase is not considered. In order to quantify the vapor concentration of only vapor phase, the dependence of the monomer fluorescence on vapor concentration, ambient pressure, and ambient temperature was tested [7]. From these results, the concentration distribution in the spray and the mean temperature distribution of the mixture were calculated from the fluorescence intensity by convergence calculation of the vapor concentration and the mean

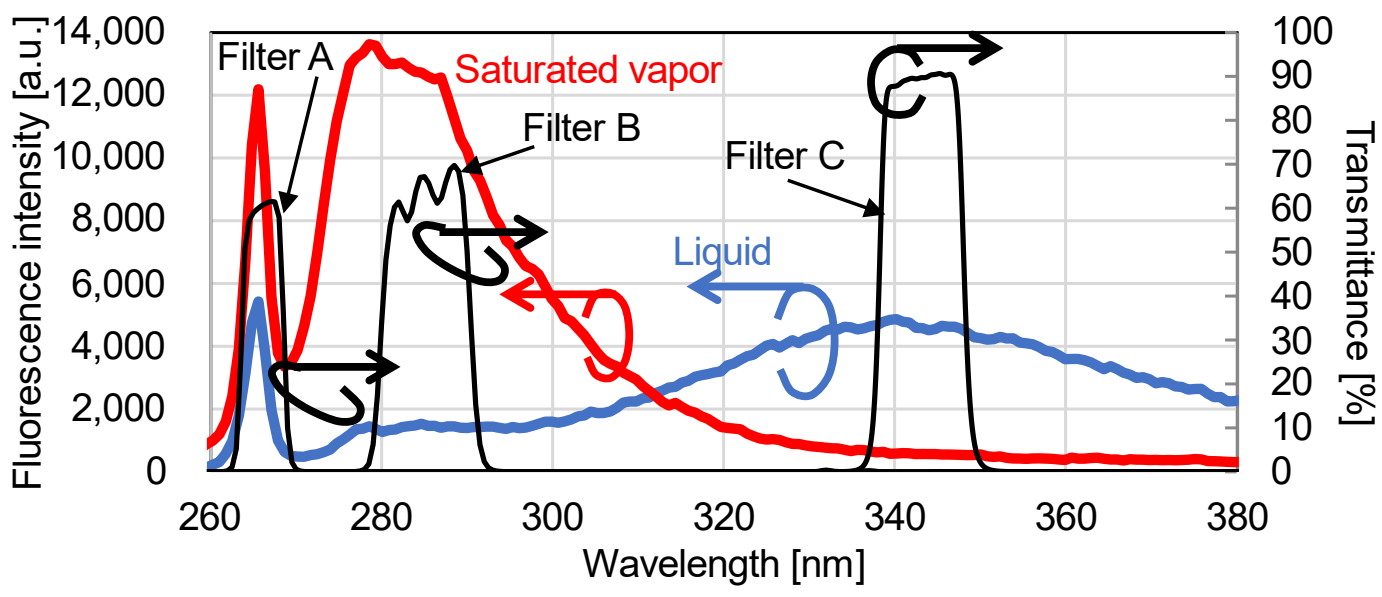

Figure 1. Monomer and exciplex fluorescence spectra of benzene/triethylamine/iso-octane mixture under $266 \mathrm{~nm}$ excitation and transmission curve for filter A, B and C. Since the monomer fluorescence of the vapor phase and the monomer fluorescence of the liquid phase are measured in filter $B$, the fluorescence of the gas and liquid phases are crossed. 
temperature of the mixture using Equation (1) [3][5]. The average temperature of the mixture of fuel vapor and ambient gas is calculated from Equation (2).

$$
\begin{aligned}
& \frac{F}{F_{5.0 \mathrm{~mol} / \mathrm{m}^{3}, 0.25 \mathrm{MPa}, 473 \mathrm{~K}}}=\frac{I_{i}}{I_{0}} \frac{C_{5.0 \mathrm{~mol} / \mathrm{m}^{3}}}{C_{5.0 \mathrm{~mol} / \mathrm{m}^{3}}} \exp \left(-k_{P} \frac{P-P_{0.25 \mathrm{MPa}}}{P_{0.25 \mathrm{MPa}}}\right) \exp \left(-k_{T} \frac{T-T_{473 \mathrm{~K}}}{T_{473 \mathrm{~K}}}\right) \\
& T_{r}=\frac{-C M_{f}\left\{c_{f l}\left(T_{s a t}-T_{l 0}\right)+L_{f}\right\}+\rho_{a} c_{a} T+C M_{f} c_{f v} T_{s a t}}{C M_{f} c_{f v}+\rho_{a} c_{a}}
\end{aligned}
$$

Where, $F$ : fluorescence intensity [a.u.], $C$ : vapor concentration $\left[\mathrm{mol} / \mathrm{m}^{3}\right], I_{0}$ : reference incident laser light intensity [mJ], $k_{p}=0.15, k_{T}=7.0$ : experimental constants [-], $M_{f}$ : molecular weight of the fuel $[\mathrm{kg} / \mathrm{mol}], c_{f f}:$ specific heat of liquid fuel $[\mathrm{J} /(\mathrm{kg}-\mathrm{K})], T_{\text {sat: }}$ saturation temperature of the fuel $[\mathrm{K}], T_{10}$ : initial temperature of the fuel $[\mathrm{K}], L_{f}$ : latent heat of vaporization of the fuel $[\mathrm{J} / \mathrm{kg}]$, $\rho_{a}$ : density of the ambient gas $\left[\mathrm{kg} / \mathrm{m}^{3}\right], c_{a}$ : specific heat of the ambient gas $[\mathrm{J} /(\mathrm{kg} \cdot \mathrm{K})], T$ : temperature of the ambient gas $[\mathrm{K}], c_{f v}$ : specific heat of the gaseous fuel $[\mathrm{J} /(\mathrm{kg} \cdot \mathrm{K})]$.

\section{Image Correction of Fluorescence Crosstalk}

In order to analyse the vapor concentration quantitatively in the two-phase mixture region of liquid and vapor, it is necessary to remove the fluorescence of the liquid phase. Therefore, the fluorescence of the liquid phase was removed from the monomer fluorescence of the twophase mixture region of liquid and vapor measured by filter $B$ using the fluorescence of the liquid phase measured by filter $C$ measured simultaneously [7][11]. Inside the spray, there are regions where only vapor exists (I), regions where vapor and liquid exist (II), and regions where only liquid exists (III). Equations (3) and (4) show the relationship between the measured fluorescence intensity $F$, transmittance $T$, and the actual fluorescence intensity $I$.

$$
\begin{aligned}
& F_{B}=\tau_{B} I_{\text {vapor }}+\tau_{B} I_{\text {liquid }} \\
& F_{C}=\tau_{C} I_{\text {vapor }}(\cong 0)+\tau_{C} I_{\text {liquid }}
\end{aligned}
$$

Here $F_{B}, F_{C}, I_{B}$, and $\tau_{C}$ are the fluorescence intensity and transmittance measured by filters and $I_{\text {liquid }}$ and $I_{\text {vapor }}$ are the actual fluorescence intensity of the liquid and vapor phases. The first term on the right-hand side of equation (4) can be ignored because the monomer fluorescence of the vapor phase is noise-level measured by filter $\mathrm{C}$. In the region where only vapor exists (I), there is no effect of crosstalk between vapor and liquid fluorescence. In order to find the first term on the right side of equation (3) in the region where vapor and liquid exist (II), the second term must be found. In the region where only droplets exist (III), the first term on the right-hand side of equations (3) and (4) can be ignored because the fluorescence of vapor is not measured, and by taking the ratio of the measured fluorescence intensity, the crosstalk constant of the fluorescence of the liquid phase to the filter B shown in equation (5) can be obtained. The crosstalk constant was calculated for the area near the nozzle $(1.2 \mathrm{~mm}$ $\times 0.3 \mathrm{~mm}$ ) during the injection period when vapor is expected to be ignorable. Using this crosstalk constant, the fluorescence intensity from vapor in the region where vapor and liquid exist (II) shown in Equation (5) can be obtained.

$$
\frac{\tau_{B}}{\tau_{C}}=\left(\frac{F_{B}}{F_{C}}\right)_{\text {III }}
$$


In the case of the application to the two-phase mixture region of liquid and vapor, the decay of the incident laser beam must take into account the scattering and absorption by droplets. However, the analysis requires the spatio-temporal droplet size distribution, which is not taken into account in this paper.

\section{Spray Imaging Experiment}

Figure 2 shows the optical system for the spray experiment, Figure 3 shows the positions of the spray and laser sheet, and Table 1 shows the experimental conditions. Figure 4 shows the Injection rate at different fuel injection pressures, which was measured by the Bosch injection rate measurement method. Mie scattering of the liquid phase was measured by filter $\mathrm{A}$, the monomer fluorescence of the liquid and vapor phases was measured filter $\mathrm{B}$, and the exciplex fluorescence of the liquid phase was measured by filter $\mathrm{C}$. The temperature inside the vessel was measured by thermocouples installed at the top and bottom. The observation window is $100 \mathrm{~mm}$ in diameter. The fuel temperature was controlled by the water-cooling flange that holds the injector. Nd:YAG laser (Quantel Q-smart850, $\lambda=266 \mathrm{~nm}$ ) was used as the light source. The beam passes through a pinhole, is reflected by a dichroic mirror, and is irradiated in the form of a sheet by two cylindrical lenses. A band-pass filter, two image intensifiers (Hamamatsu Photonics: C4078-01), and two CCD cameras (Hamamatsu Photonics: ORCA-R2) were placed orthogonal to the laser sheet. Camera A measured fluorescence at a wavelength of $285 \mathrm{~nm}$, and camera B measured fluorescence at a wavelength of $343 \mathrm{~nm}$ and scattered light at a wavelength of $266 \mathrm{~nm}$ by spectroscopy with a stereoscope lens. The energy transmitted through the dichroic mirror was measured to correct for the variation in pulse energy. Since the fluorescence intensity is proportional to the intensity of the incident laser light according to Equation (1), image correction was required, and the images were corrected based on the assumption that the laser sheet light had a Gaussian intensity distribution [6].

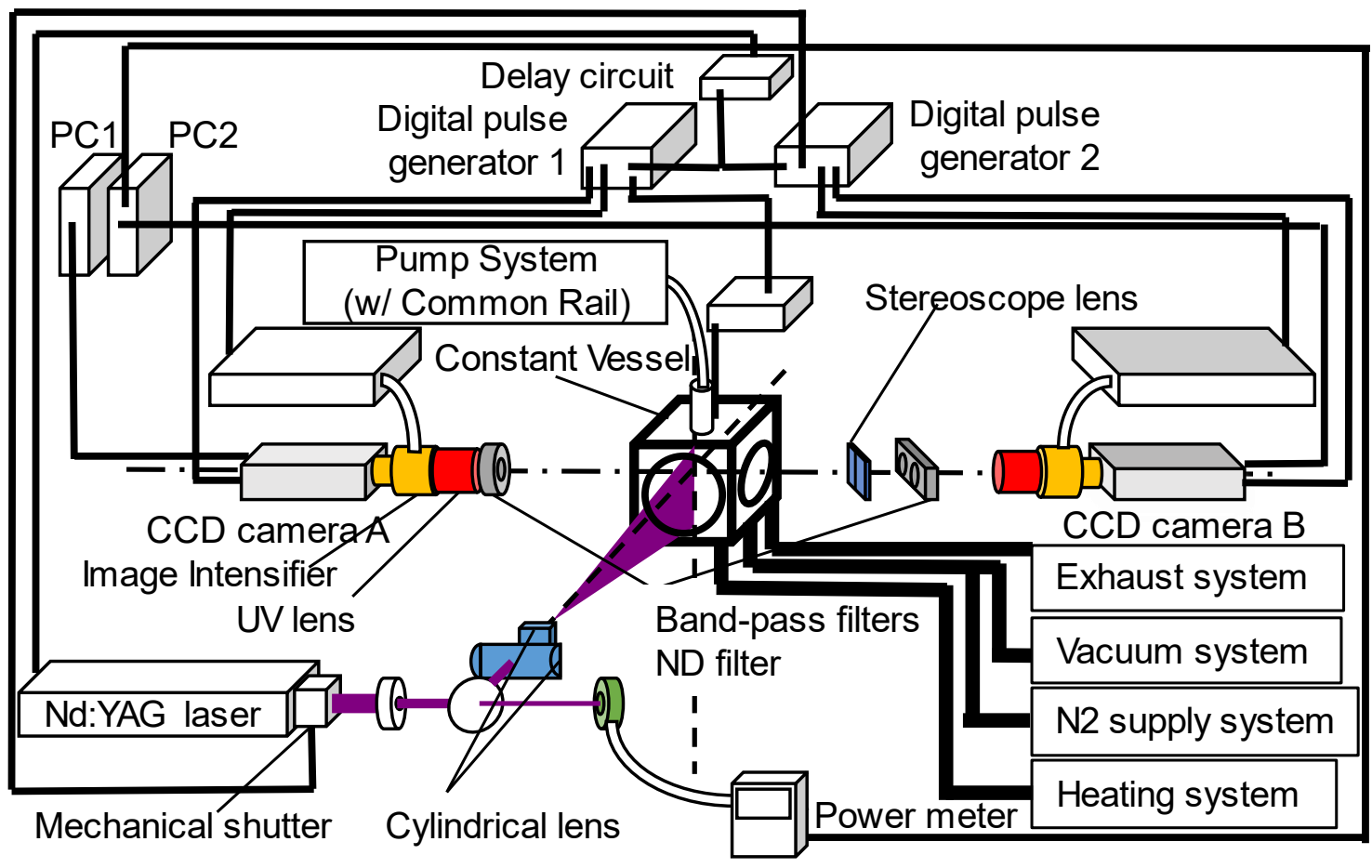

Figure 2. Optical system for simultaneous measurement of fluorescence from the spray at three different wavelengths using bandpass filters and stereoscope lens. 
Table 1. Experimental conditions.

\begin{tabular}{c|c}
\hline \hline Test nozzle & Multi Hole $(6-\varphi 0.13 \mathrm{~mm})$ \\
\hline Test Fuel [vol\%] & $\begin{array}{c}\text { Iso-octane:92, } \\
\text { Benzene:4, Triethylamine:4 }\end{array}$ \\
\hline $\begin{array}{c}\text { Differential Pressure of } \\
\text { injection } \Delta P_{i n j}[\mathrm{MPa}]\end{array}$ & $5,15,25$ \\
\hline $\begin{array}{c}\text { Injection Duration } t_{\text {inj }}[\mathrm{ms}] \\
\text { Injection Fuel Amount } \\
q_{\text {injhole }}[\mathrm{mg}]\end{array}$ & $1.93,1.25,1.03$ \\
\hline Fuel Temperature $T_{f}[\mathrm{~K}]$ & 1.2 \\
\hline Ambient Gas & 343 \\
\hline $\begin{array}{c}\text { Ambient Temperature } \\
T_{a}[\mathrm{~K}]\end{array}$ & $\mathrm{N}_{2}$ \\
\hline Ambient Density $\rho_{a}\left[\mathrm{~kg} / \mathrm{m}^{3}\right]$ & 505 \\
\hline Ambient Pressure $P_{a}[\mathrm{MPa}]$ & 1.87 \\
\hline
\end{tabular}

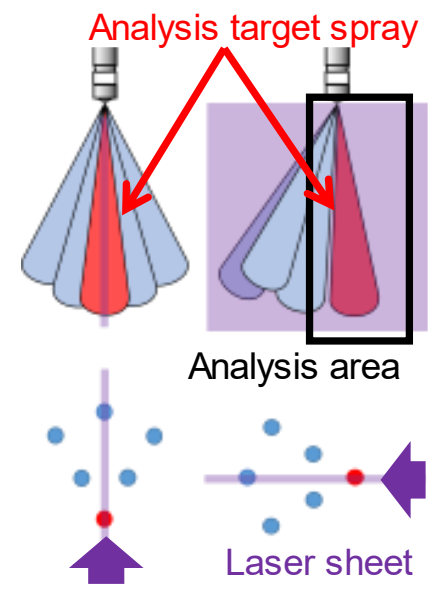

Figure 3. Relation between laser sheet and spray pattern.

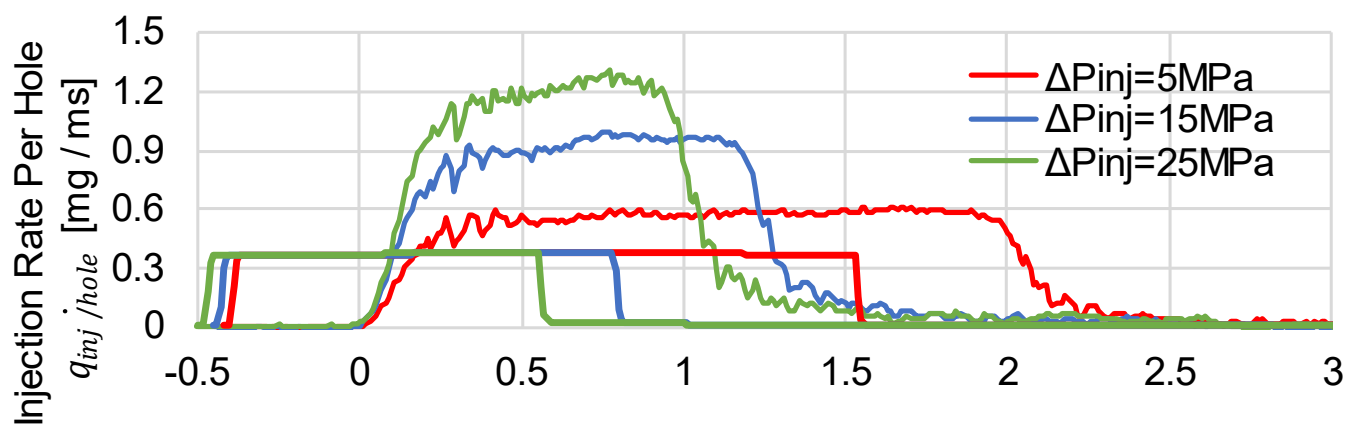

After start of injection $t[\mathrm{~ms}]$

Figure 4. Injection rate at different fuel injection pressures measured by the Bosch injection rate measurement method.

\section{Spatial distribution of liquid and vapor phases}

Figure 5 shows the fluorescence intensity of the liquid phase and vapor concentration distributions. Near the nozzle, no vapor is formed, and the fluorescence intensity of the liquid phase is very high. The fluorescence intensity of the liquid phase and the vapor concentration decrease with distance from the spray centre axis. In addition, most of the region is covered with a mixed of liquid and vapor. Figure 6 shows the tip penetrations of the liquid and vapor phases with different fuel injection pressures. In this experiment, the same nozzle was used, the fuel injection pressure was changed, and the injection amount was constant, so the injection period was different. Since the increase in fuel injection pressure increases the fuel injection velocity, the tip penetrations of the liquid and vapor phases increases with the increase in fuel injection pressure. The liquid phase region of the spray could not evaporate completely and remained in low concentration in the mixture. 


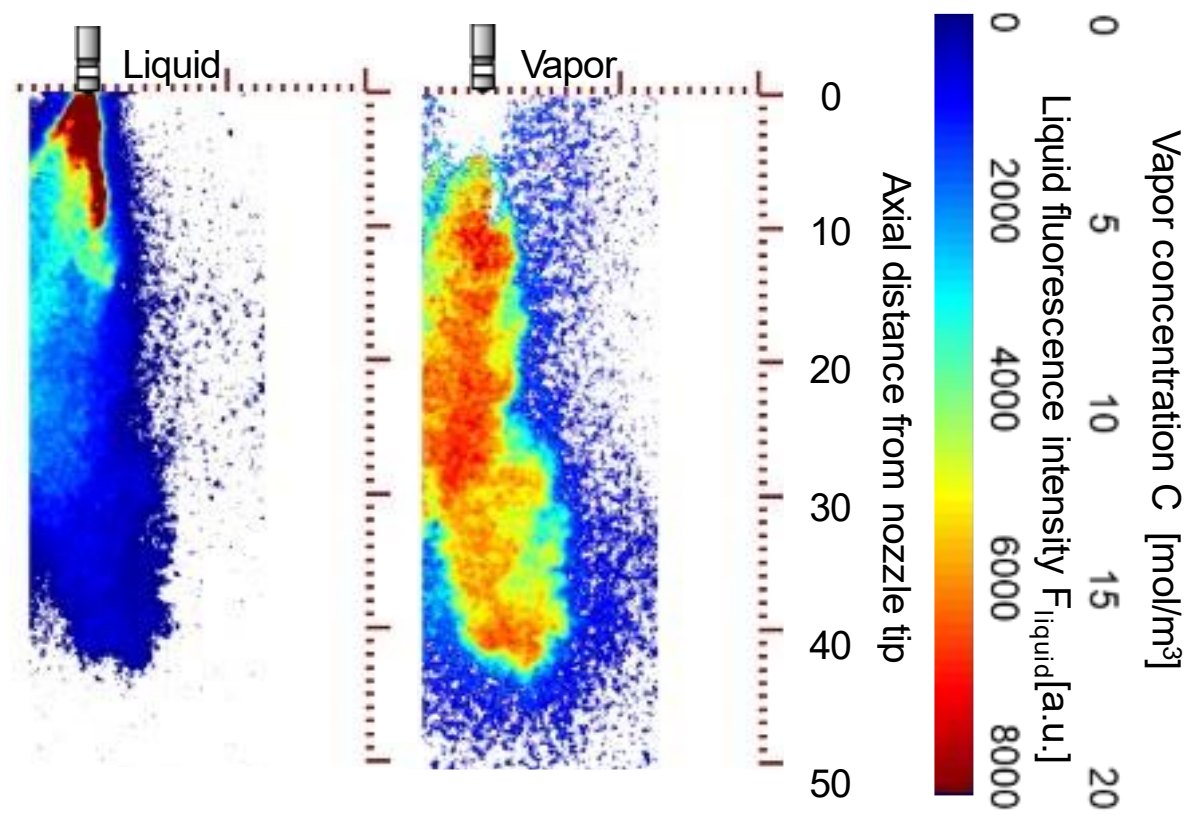

Figure 5. Liquid fluorescence intensity and vapor concentration distributions at ASOI : $1.00 \mathrm{ms,}$

$P_{\text {inj }}: 15 \mathrm{MPa}, P_{a}: 0.28 \mathrm{MPa}, \rho_{a}: 1.87 \mathrm{~kg} / \mathrm{m}^{3}, \quad T: 505 \mathrm{~K}, t_{\text {inj }}: 1.25 \mathrm{~ms}, q_{\text {inj/hol }}: 1.2 \mathrm{mg}, T_{\text {sat }}: 413 \mathrm{~K}$.

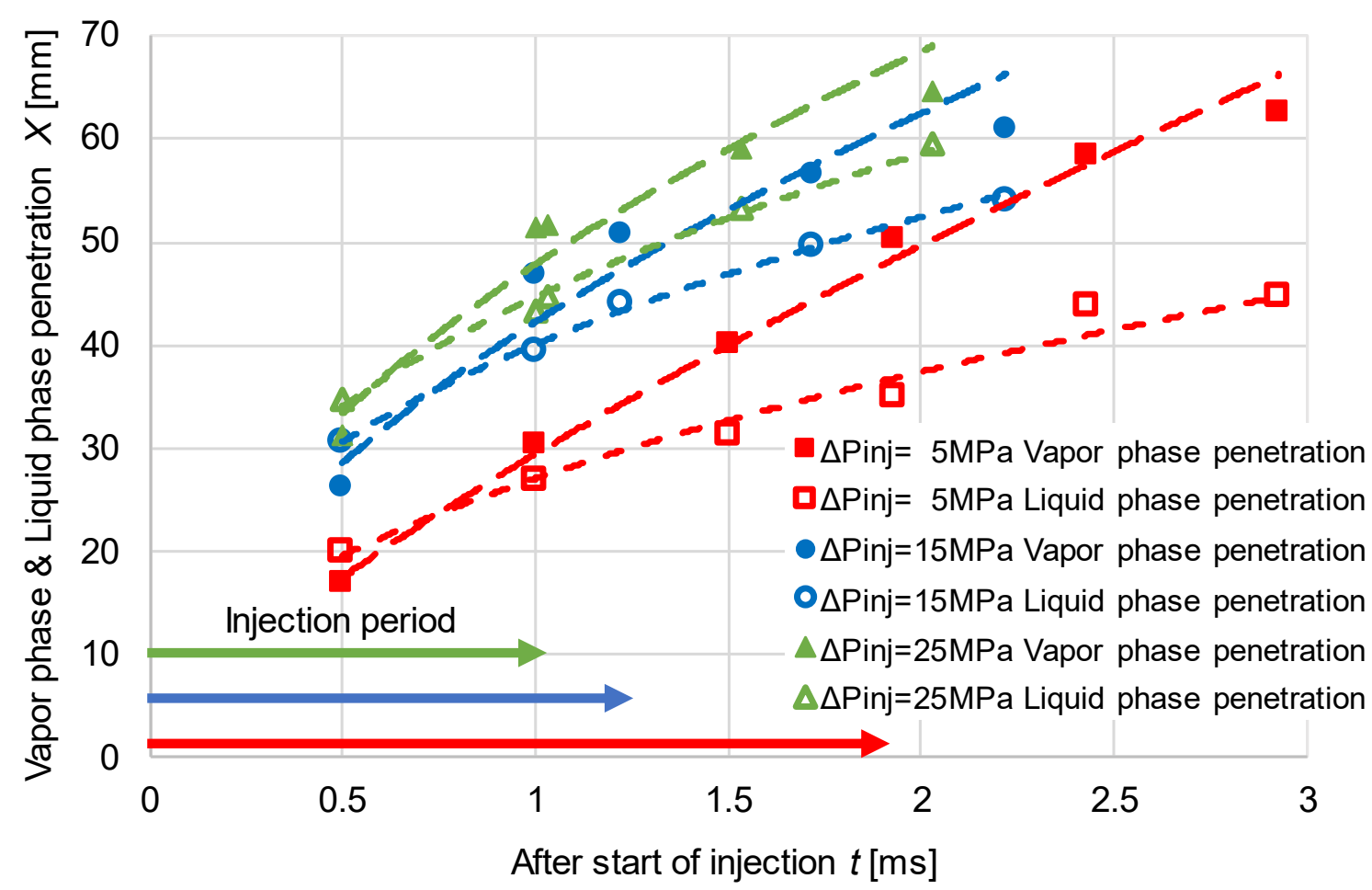

Figure 6. The tip penetrations of the liquid and vapor phases at different fuel injection pressures. $P_{a}: 0.28 \mathrm{MPa}, \rho_{a}: 1.87 \mathrm{~kg} / \mathrm{m}^{3}, T: 505 \mathrm{~K}, t_{i n j}: 1.25 \mathrm{~ms}, q_{\text {inj } / \mathrm{hol}}: 1.2 \mathrm{mg}, T_{\text {sat }}: 413 \mathrm{~K}$. 
Figure 7 shows the concentration distribution of the liquid and vapor phases $0.5 \mathrm{~ms}$ after the end of injection. The relative frequency distribution obtained from the concentration distribution of the vapor phase is shown in the figure 8 . The cross-sectional area of the vapor phase obtained from the images is similar, and there is no significant difference in the relative frequency distribution of concentration with different fuel injection pressures. This indicates that the effect of fuel injection pressure on the state of the mixture distribution is small. On the other hand, the cross-sectional area of the liquid phase decreases significantly with increasing fuel injection pressure. This is because the total surface area increases due to the atomization effect of the increased fuel injection pressure, which enhances evaporation.

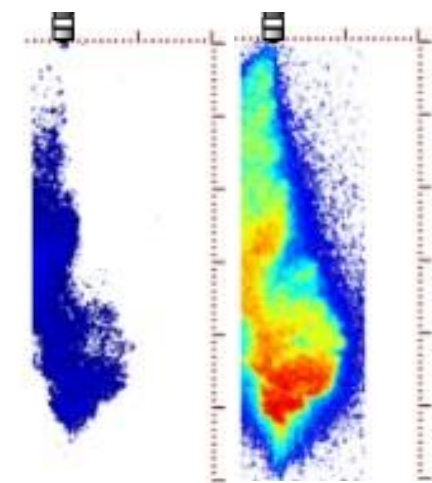

$$
\text { Liquid Vapor }
$$$$
\Delta P_{i n j}: 5 \mathrm{MPa}
$$

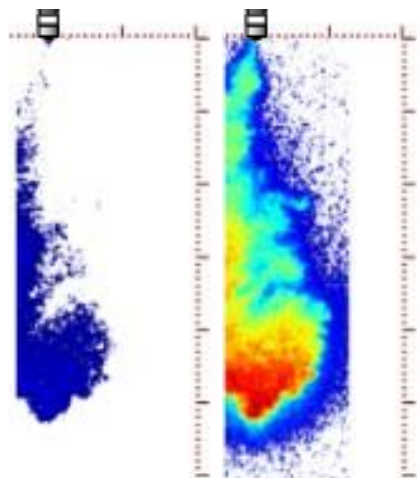

Liquid Vapor $\Delta P_{i n j}: 15 \mathrm{MPa}$

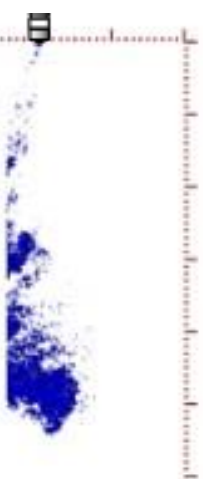

Liquid

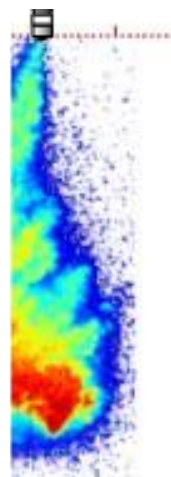

Vapor

Liquid fluorescence intensity $F_{\text {liquid }}[$ a.u.] $0 \quad 2000$

$$
\Delta P_{i n j}: 25 \mathrm{MPa}
$$

Vapor concentration $\quad C\left[\mathrm{~mol} / \mathrm{m}^{3}\right] \quad 0$

Figure 7. Liquid fluorescence intensity and vapor concentration distributions at EOI : $0.50 \mathrm{~ms}$ $P_{a}: 0.28 \mathrm{MPa}, \rho_{a}: 1.87 \mathrm{~kg} / \mathrm{m}^{3}, T: 505 \mathrm{~K}, t_{\text {inj }}: 1.25 \mathrm{~ms}, q_{\text {inj/hol }}: 1.2 \mathrm{mg}, T_{\text {sat }}: 413 \mathrm{~K}$.

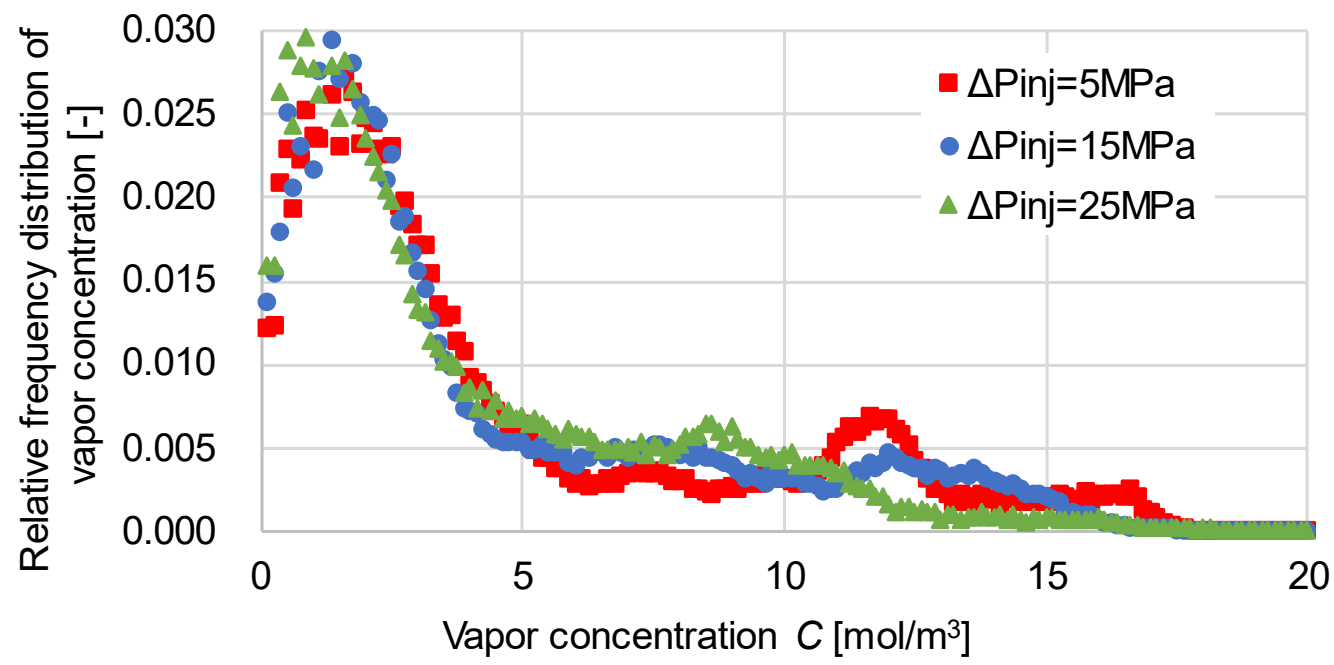

Figure 8. Relative frequency distribution of vapor concentration. There is no significant difference at different fuel injection pressures. 


\section{Summary and Conclusions}

In this paper, the quantitative analysis of vapor concentration using the exciplex fluorescence technique was used to evaluate the gasoline spray mixture at different fuel injection pressures. This quantitative method takes into account the crosstalk of fluorescence between the liquid and vapor phases by measuring different wavelength information captured simultaneously. These analyses show that the mixture in the spray still contains low concentration of liquid phase, and the liquid phase penetration increases as the fuel injection pressure increases. In addition, the fuel injection pressure has a small effect on the state of the mixture, but the liquid phase area is greatly reduced with increasing injection pressure.

\section{Nomenclature}

C Vapor concentration $\left[\mathrm{mol} / \mathrm{m}^{3}\right]$

$c_{a} \quad$ Specific heat of the ambient gas $[\mathrm{J} /(\mathrm{kg} \cdot \mathrm{K})]$

$c_{f v} \quad$ Specific heat of the gaseous fuel $[\mathrm{J} /(\mathrm{kg} \cdot \mathrm{K})]$

$C_{f l} \quad$ Specific heat of liquid fuel $[\mathrm{J} /(\mathrm{kg} \cdot \mathrm{K})]$

$F \quad$ Fluorescence intensity [a.u.]

I $\quad$ Actual fluorescence intensity [a.u.]

Io $\quad$ Reference incident laser light intensity [mJ]

$L_{f} \quad$ Latent heat of vaporization of the fuel $[\mathrm{J} / \mathrm{kg}]$

$M_{f} \quad$ Molecular weight of the fuel $[\mathrm{kg} / \mathrm{mol}]$

$T \quad$ Temperature of the ambient gas [K]

$T_{\text {sat }} \quad$ Saturation temperature of the fuel $[\mathrm{K}]$

$T_{10} \quad$ Initial temperature of the fuel $[\mathrm{K}]$

$\rho_{a} \quad$ Density of the ambient gas $\left[\mathrm{kg} / \mathrm{m}^{3}\right]$

$\tau \quad$ Transmittance [-]

\section{References}

[1] Tsujimura, T., Mita, T., Zhili, C. and Goto, S., 2008, Marine engineering: journal of the Japan Institution of Marine Engineering, 43, (2), pp. 273-278 (in Japanese).

[2] Kojima, H., Takahashi, E., Tsujimura, T., Furutani, H. and Kashiwazaki, T., Sep. 1. -4, 2015, Fuels \& Lubricants Meeting (2015).

[3] Senda, J., Kanda, T., Kobayashi, M. and Fujimoto, H., 1997, SAE Technical Paper, Paper No. 970796.

[4] Adachi, M., McDonell, V., Tanaka, D., Senda, J. and Fujimoto, H., 1997, SAE Technical Paper, Paper No. 970871.

[5] Suzuki, M., Nishida, K. and Hiroyasu, H., 1993, SAE Technical Paper, Paper No. 930863.

[6] Matsuda, D., Matsumura, E., Senda, J., 2020, Transactions of the JSME (in Japanese), 86 (888), Pages 20-00099 (in Japanese).

[7] Matsuda, D., Matsumura, E., Senda, J., 2020, Transactions of the JSME (in Japanese), 86 (891), Pages 20-00294(in Japanese).

[8] Melton, L. A., 1983, Applied Optics, 22 (14), pp. 2224-2226.

[9] Melton, L. A., 1993, Applied Spectroscopy, 47 (6), pp. 782-786.

[10] Froba, A.P., Rabenstein, F., Munch, U. and Leipertz, 1998, Combustion and Flame, 112, pp. 199-209.

[11] Byeongil AN, Yasuhiro DAISHO, 2001, Transactions of the Japan Society of Mechanical Engineers Series B, 67 (664), Pages 3169-3174. 